\title{
Assessing Climate Effects on Railway Earthworks Using MASW
}

S. Donohue* (Queen's University Belfast), D.A. Gunn (British Geological Survey), P. Bergamo (Queen's University Belfast), E. Hughes (Queen's University Belfast), B. Dashwood (British Geological Survey), S. Uhlemann (British Geological Survey), J.E. Chambers (British Geological Survey) \& D. Ward (In-Situ Site Investigation)

Summary

Many parts of the UK's rail network were constructed in the mid-19th century long before the advent of modern construction standards. Historic levels of low investment, poor maintenance strategies and the deleterious effects of climate change have resulted in critical elements of the rail network being at significant risk of failure. The majority of failures which have occurred over recent years have been triggered by extreme weather events. Advance assessment and remediation of earthworks is, however, significantly less costly than dealing with failures reactively. It is therefore crucial that appropriate approaches for assessment of the stability of earthworks are developed, so that repair work can be better targeted and failures avoided wherever possible. This extended abstract briefly discusses some preliminary results from an ongoing geophysical research project being carried out in order to study the impact of climate or seasonal weather variations on the stability of a century old railway embankment on the Gloucestershire Warwickshire steam railway line in Southern England.

\section{Introduction}

Many parts of the UK's rail network were constructed in the mid to late 19th century, long before the advent of modern construction standards. Historic levels of low investment, poor maintenance strategies and the deleterious effects of climate change have resulted in critical elements of the rail network being at significant risk of failure. A recent study conducted by Network Rail, who own the largest network of earth structures in the UK, has revealed that $50 \%$ (or $5000 \mathrm{~km}$ ) of their network of earthworks are considered to be in a "poor" or "marginal" condition (Network Rail 2011). According to Department of Transport Rail Accident Investigation an average of 65 earthworks failures per year were recorded during the period from $2004 / 5$ to $2008 / 9$ (RAIB 2008). The majority of these failures occurred as cutting and embankment slips and a large portion were triggered by localised extreme weather events (Network Rail 2011). Although there has been little change in winter precipitation over the last half century, during this time there has been an increase in the proportion of winter rainfall in the UK resultant from heavy precipitation events (Jenkins et al. 2009). Extreme seasonal increases in pore water pressure (reductions in suction pressure) resultant from excessive rainfall may significantly reduce the strength of earthworks leading to possible failure if triggered, for example, by an extreme weather event (Wilks, 2010). It is not just extreme wet weather which causes failures, dry conditions can lead to desiccation and cause cracking of slope surfaces, increasing their permeability and providing pathways for rainfall infiltration. When the effects of wetting and drying are combined, seasonal cyclical patterns may cause shrinking, swelling and strain softening of the fill materials which may result in serviceability failures and eventual earthwork collapse (Kovacevic et al. 2001). Advance assessment and remediation of earthworks is significantly less costly than dealing with failures reactively. It is therefore crucial that approaches for assessment of earthwork stability are developed, so that repair work can be targeted and failures avoided wherever possible. Geophysical methods, when used as complimentary tools together with traditional geotechnical investigations, are ideally suited for earthwork investigations (e.g. Donohue et al. 2011, 2012; Chambers et al. 2014). In addition to being non-invasive a number of these techniques are cost-effective and rapid, allowing detailed $2 \mathrm{D}$ and $3 \mathrm{D}$ information to be obtained, with repeated observations permitting temporal variations to be measured. This may be particularly useful if the measured geophysical properties are calibrated with relevant geotechnical parameters. This extended abstract briefly discusses ongoing geophysical research in order to study the impact of climate or seasonal weather variations on the stability of a century old railway embankment in Southern England. 


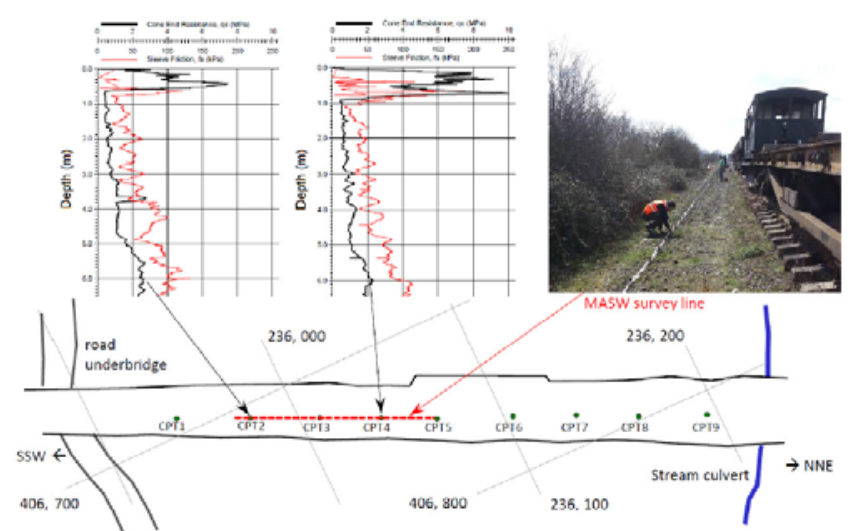

Figure 1 Laverton embankment site lavout map, showing the location of Cone Penetration Test (CPT) profiles and the MASW survey line. Example CPT profiles are shown inset along with a picture of MASW data acquisition setup using a landstreamer.

\section{Laverton Embankment}

The railway embankment being investigated in this study is part of the heritage Gloucestershire Warwickshire Steam Railway and is located near the village of Laverton, in the Cotswolds region of Southern England. The embankment is approximately $5 \mathrm{~m}$ high and is believed to have been constructed circa 1900 - 1906 via end tipping of local Charmouth Mudstone. Currently the embankment comprises a $0.9 \mathrm{~m}$ thick upper layer of ballast fouled with fines, ash and soil (rich in humus), underlain by about $4 \mathrm{~m}$ of a high plasticity clay fill (Charmouth Mudstone). A number of significant earthwork failures on the Gloucester Warwickshire Railway have occurred over recent years and there is also evidence of previous movement at the Laverton embankment. A site layout map is illustrated in Figure 1, which also shows the results of two Cone Penetration Test (CPT) profiles carried out at the site. From the CPT data it appears that the embankment may have been constructed in two lifts, possibly with the boundary at about $3 \mathrm{~m}$ depth. Generally, the upper interval exhibits very low penetration resistances (qc) of (between $0.5-1 \mathrm{MPa}$ ), while the fill between $3-5 \mathrm{~m}$ exhibits slight greater qc (between 1 - 1.3 MPa). Sampling of the clay immediately beneath the ballast around CPT 3 indicated high levels of moisture and weathering. Below the embankment base (around $5 \mathrm{~m}$ ) qc increases considerably as the cone is pushed into the underlying formation.

In order to investigate the effect of climate or seasonal variation on the embankment, data from a range of near surface geophysical methods (Multichannel Analysis of Surface Waves, Seismic refraction \& Electrical Resistivity Tomography) and permanently installed field sensors (for measuring pore water pressure, soil moisture, electrical conductivity, temperature, rainfall, wind speed, relative humidity) are being regularly monitored at the site. This extended abstract will briefly discuss some of the initial MASW results that have been acquired.

\section{Multichannel analysis of surface waves (MASW)}

The use of the MASW approach for the estimation of shear-wave velocity (Vs) profiles has received considerable attention over the last number of years (e.g. Park et al. 1999; Donohue and Long 2008). According to elastic theory, the small strain shear modulus, Gmax, is related to Vs by:

$G \max =\rho \cdot V s^{2}$

where Gmax = shear modulus $(\mathrm{Pa}), \mathrm{V} s=$ shear wave velocity $(\mathrm{m} / \mathrm{s})$ and $\rho=$ density $(\mathrm{kg} / \mathrm{m} 3)$. Gmax (or $V s$ ) has been found to be dependent on effective stress and therefore pore/suction pressures. A number of authors have explored the relationship between soil suction and Gmax on laboratory samples for a range of materials (e.g. Mancuso et al 2002, Mendoza and Colmenares 2006). Much of this work has been carried out on soil samples in a controlled laboratory setting, with limited field verification.

MASW data was acquired along the crest of the Laverton embankment using a roll-along approach with a land streamer (Figure 1) consisting of 24 plate coupled $4.5 \mathrm{~Hz}$ geophones with a $1 \mathrm{~m}$ inter geophone spacing and a $2 \mathrm{~m}$ source to first receiver distance. A $4.5 \mathrm{~kg}$ sledgehammer was used to generate the seismic data and shots were acquired at $5 \mathrm{~m}$ intervals over a $100 \mathrm{~m}$ section of railway embankment. As discussed above, seismic data acquisition is ongoing and is being acquired at regular intervals throughout the year, along the exact same profile. The results are also being analysed with respect to data from the permanently installed field sensors. For this abstract, some preliminary results, acquired in July and November 2013 are shown. It should be noted 
that the July 2013 data acquisition followed a period of particularly warm and dry weather, whereas the November data acquisition followed a period of wet weather. All dispersion curves picked following the July and November 2013 acquisitions are shown in Figure 2. Normally dispersive phase velocity - frequency relationships was observed for all profiles, dominated by the fundamental mode Raleigh wave. As shown, the phase velocities recorded were consistently higher during July, particularly at frequencies greater than $15 \mathrm{~Hz}$ (corresponding to the approximate embankment height). Overall, the phase velocities are also found to increase with increasing distance $(X)$ along the embankment crest. Vs models were estimated using the approach detailed by Xia et al. (1999). A number of different initial models were selected in order to test the robustness of the inversion and to determine the model with the lowest misfit. In order to reduce the non-uniqueness of the inversion, P-wave velocities from the seismic refraction surveys were included as apriori information. Each inversion was stopped after the overall RMS error was less than $2 \mathrm{~m} / \mathrm{s}$ and all converged within 4 iterations. It was consistently found that a ten layer initial model produced the lowest RMS error. 2D depth sections were generated by combining the inverted 1D Vs profiles. 2D Vs profiles for July and November 2013 are illustrated in Figure 3, for the upper $5.5 \mathrm{~m}$. As shown, the embankment distribution of Vs was consistently less than $150 \mathrm{~m} / \mathrm{s}$, which corresponds to a Gmax of less than 30MPa indicating a soft embankment fill, consistent with the CPT data. Vs increases considerably below $5 \mathrm{~m}$ depth at the boundary between the embankment fill and the underlying formation. As expected, following the variation in dispersion curves observed between July and November, a general reduction in inverted Vs was observed across the embankment in November when compared with July. The mean difference in inverted Vs is just under $10 \%$. As a significant amount of rainfall was recorded in the weeks prior to the November MASW acquisition, it is possible that this reduction in Vs reflects a reduction in soil suction, possibly as a result of rainfall infiltration. Research is currently being carried out to investigate the in-situ relationship between Vs, soil moisture and soil suction (from field sensors). This should provide a quantitative explanation for the observed variations in Vs. This work will be disseminated at a later date.
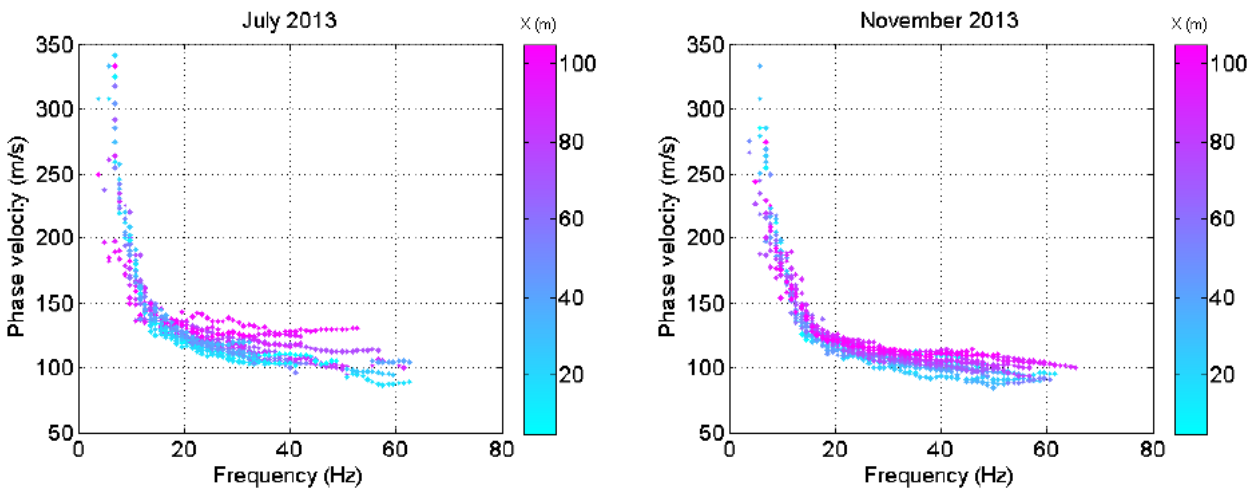

Figure 2 Dispersion curves picked for the July and November MASW data acquisitions.
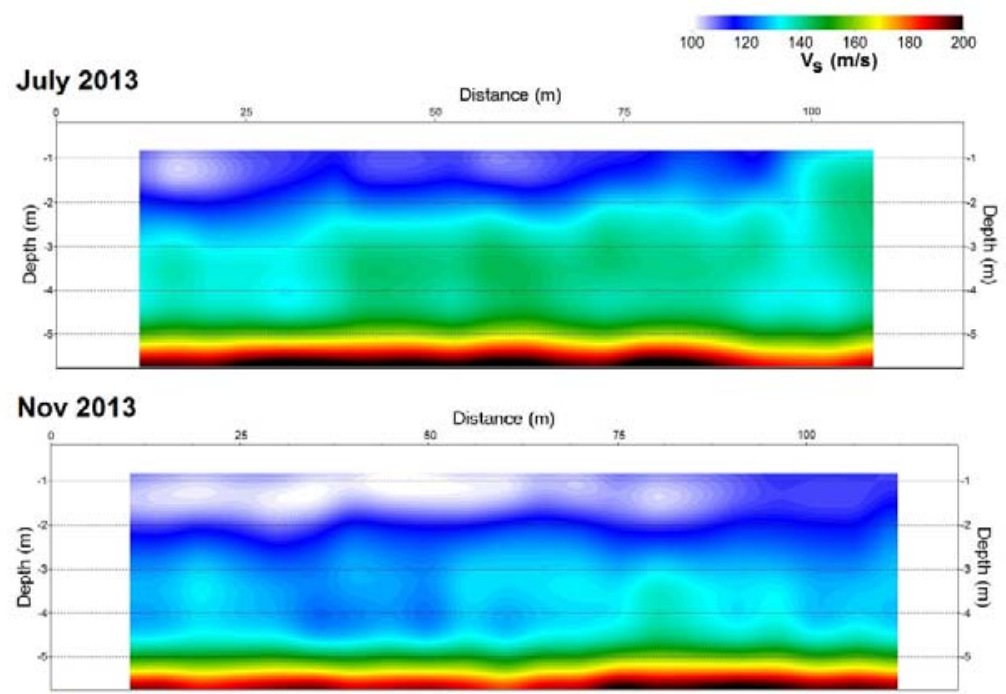

Figure 3 Inverted $2 D V_{s}$ profiles from July and November 2013 from the Laverton embankment. 


\section{Conclusions}

Advance assessment and remediation of earthworks is significantly less costly than dealing with failures reactively. It is therefore crucial that appropriate approaches for assessment of the stability of earthworks are used and developed, so that repair work can be better targeted and failures avoided wherever possible.

This extended abstract has briefly discussed some early results from an ongoing geophysical research project being carried out in order to study the impact of climate or seasonal weather variations on the stability of a century old railway embankment on the Gloucestershire Warwickshire steam railway line in Southern England. The embankment itself is constructed from a high plasticity clay fill and CPT profiles indicate that this material is very soft. A number of significant earthwork failures on the railway have occurred over recent years and there is also evidence of previous movement at the test embankment. In this abstract, some of the preliminary MASW data acquired at the site was discussed. A general reduction in Raleigh wave phase velocity and corresponding inverted Vs across the embankment was observed in November 2013 when compared with July 2013. As a significant amount of rainfall was recorded at the site in the weeks prior to the November MASW data acquisition, it is likely that this reduction in velocity reflects a reduction in soil suction at this location, possibly as a result of rainfall infiltration. Research is currently being carried out to investigate the Insitu relationship between Vs, soil moisture and soil suction. This should provide a quantitative explanation for the observed seasonal variations in Vs.

\section{Acknowledgements}

This work was funded by the Engineering and Physical Sciences Research Council (EPSRC). The contributions to this work from Ben Dashwood, Sebastian Uhlemann, Jon Chambers and David Gunn are published with permission from the Executive Director of The British Geological Survey (NERC).

\section{References}

Chambers, J.E., Gunn, D.A., Wilkinson, P.B., Meldrum, P.I., Haslam, E., Holyoake, S., Kirkham, M., Kuras, O., Merritt, A. and Wragg, J. [2014] 4D electrical resistivity tomography monitoring of soil moisture dynamics in an operational railway embankment. Near Surface Geophysics, 12(1), 61-72. Donohue S. and Long, M. [2008] An assessment of the MASW technique incorporating discrete particle modelling. Journal of Environmental and Engineering Geophysics, 13, 57-68.

Donohue, S., Gavin, K. and Tolooiyan, A. [2011] Geophysical and geotechnical assessment of a railway embankment failure. Near Surface Geophysics, 9(1), 33-44.

Donohue, S., Gavin, K. and Tolooiyan, A. [2012] Railway earthwork stability assessment using geophysics. In: Quental Coutinho, R. and Mayne, P. (Eds) Geotechnical and Geophysical Site Chacterisation 4, Vol. 2. London: Taylor and Francis, 1519-1525

Jenkins, G.J. et al. [2009] UK Climate Projections: Briefing report (UKCP09). Met Office Hadley Centre, Exeter, UK.

Kovacevic, N., Potts, D.M. and Vaughan, P.R. [2001] Progressive failure in clay embankments due to seasonal climate changes. Proceedings of the 15th International Conference on Soil Mechanics and Geotechnical Engineering, Istanbul, Turkey, Expanded Abstracts, 2127-2130.

Network Rail [2010] Asset Management Policy: Justification for Civil Engineering Policy.

Mancuso, C., Vassallo, R.M. and d'Onofrio, A. [2002] Small strain behavior of a silty sand in controlledsuction resonant column - torsional shear tests. Canadian Geotechnical Journal 39, 22-31.

Mendoza, C.E. and Colmenares, J.E. [2006] Influence of the Suction on the Stiffness at Very Small Strains, Proceedings of the Fourth International Conference on Unsaturated Soils, doi:10.1061/40802(189)40.

Park, C.B., Miller, D.M. and Xia, J. [1999] Multichannel Analysis of surface. Geophysics, 64(3), 800-808.

RAIB [2008] Rail Accident Report. Network Rail's Management of Existing Earthworks. Rail

Accident Investigation Branch, Department for Transport 25/2008.

Wilks, J.H. [2010] Forecasting transportation infrastructure slope failures in a changing climate. 11th $B G A$ Young Geotechnical Engineers' Symposium.

Xia, J., Miller, R.D. and Park, C.B. [1999] Estimation of near surface shear wave velocity by inversion of Raleigh waves. Geophysics, 64, 691-700. 